\title{
'[E]k wat seunsagtig onbehoed wou leef'
}

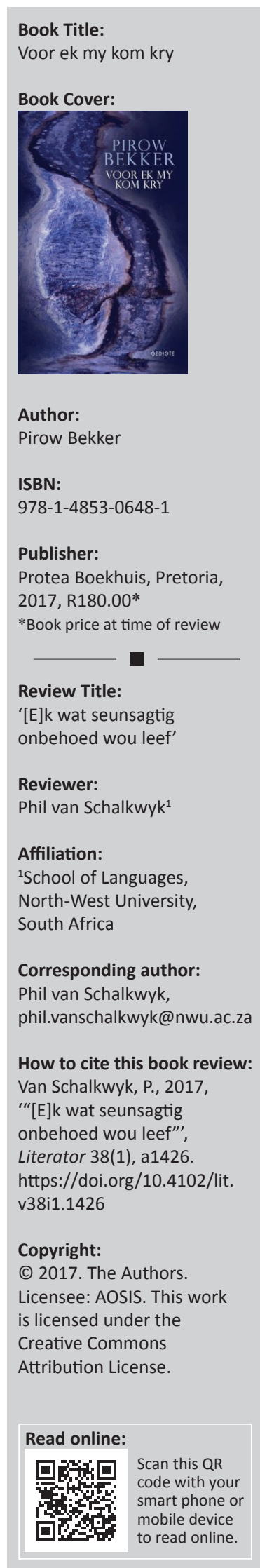

Pirow Bekker (1935-) se tiende digbundel, Voor ek my kom kry, het vanjaar by Protea Boekhuis verskyn. Hiermee word die indrukwekkende laat groeifase wat sy digkuns die afgelope anderhalf dekade toon, op oortuigende wyse voortgesit. Alhoewel hierdie bundel sy direkte voorganger, Atlas teen die vergeetrivier (2013), nie oortref nie, kan aangevoer word dat dit laasgenoemde minstens ewenaar. Beide werke vertoon 'n betreklik hegte konstruksie, op makro- sowel as mikrovlak.

Die nuutste versameling hou die vorige ouderdomsbundels se gemoedelik-uitdagende verkenning van die ouderdom en verganklikheid vol, maar hier tree tog iets van 'n sterker besef van finaliteit en futiliteit in. In hierdie verband is die bundeltitel funksioneel. Dit resoneer met die slotgedig waarvan die titel, 'Toe ek my kom kry', 'n bekende Afrikaanse uitdrukking is wat beteken: 'toe ek begin oplet, daaraan dink; toe ek tot my sinne kom' (Odendal \& Gouws 2005:634). Dit het te make met onkant gevang word, wat in die bundeltitel geïntensiveer word deur die vervanging van 'toe' met 'voor'. Hierdie 'onvoorbereidheid' het betrekking op die naderende afskeid van die lewe, maar ook die skrywerlike 'boedel' (vgl. die gedig 'Boedel', bl. 61).

Die bundel begin met die losstaande openingsgedig, 'Skeppingsprokie'. Hierdie gedig raam die digterlike bestekopname van die persoonlike doen en late wat Bekker in die bundel onderneem, met die verhaal van die mens wat in 'n soort laboratoriumtenk - as deel van 'n groter eksperiment deur 'n witjasman' met 'binnehandskoene steriel', 'eers in sy kwaad [gesterk]' word. Ná hierdie raamgegewe, waardeur spesifiek die skeppings- en paradyskode geaktiveer word, volg agt afdelings wat elk 'n eie aksent besit, maar tog inmekaar vloei.

Die eerste afdeling, Aarde inbegrepe, bestaan uit gedigte van besinning oor die aarde en die gang van die tyd, en keer terug na gevestigde motiewe in Bekker se oeuvre, veral dié van die son. Die sterk openingsgedig van hierdie afdeling, 'Wesp', stel Bekker se bekende spel met kontraste van donker en lig (die deurbrekende lig) aan die orde. Die vrees vir die wesp se angel, wat vindingryk by wyse van variasie op 'n bekende liedjie te berde gebring word ('O brandepyn laat my staan!', bl. 10), loop uit op die kragtige slotbeeld: 'want sy lyf is wispelturig,/die sonnige sekel van die donkermaan' (bl. 10). Die gedig 'Versoening ná die karsinoom' hervat die verhaal van velkanker wat in die 1993-bundel, Rasuur, vertel word in gedigte soos 'Die storie van 'n liefdesbyt' (Bekker 1993:69) en 'Karsinoom en melanoom' (Bekker 1993:66): velkanker is die negatiewe teensy van die aanbidding van 'Sol Invictus' ('Versoening ná die karsinoom', bl. 12). Die son word in 'Versoening ná die karsinoom' eers as 'tweegesig' voorgehou, en die spreker gee te kenne dat sy siel al 'toentertyd sy rug op jou [die son] gekeer' (bl. 12) het. Die son word die stryd aangesê, maar die gedig kom tog by versoening uit omdat ingesien word dat die son steeds in verband staan met die koms van "n nuwe dag', en sluit soos volg: 'En deur die rokerigheid/van 'n slagveld lê jul jul wapens neer' (bl. 12).

Erd-af, die tweede afdeling, bied onder meer, deur'n intertekstuele gesprek met Leipoldt (spesifiek in die gedig 'Erd-af mens', bl. 28), 'n heroriëntering van die 'erd-af' ek binne omgewende werklikhede wat ook aan't verval is, maar wel met hoopvolle projeksie. In 'Met voelhorings in die land' word doelbewus teruggedraai na die land om wonde te heel, 'nie met komfrie nie uit vreemde taal, / maar met woorde uit jou eie hart' (bl. 23), en in 'Ommekeer' wys 'die donderwolk 'n glansrug/vir wat hy agterlaat' (bl. 24). Hierdie afdeling eindig met die opbeurende 'Kersnagreis' waarin verklaar word: 'Gewillig soos 'n kind gee ek my oor aan die reis' (bl. 30).

Die 'dans' met eksistensie in 'n omgewing geteister deur uiteenlopende soorte probleme word in afdeling drie, Stormvorme, voortgesit, onder meer in gesprek met, nogeens, Leipoldt ('Vormloos op Boggomsbaai', bl. 32) maar ook Marais ('Oor Eugène Marais se Klaas Vakie', bl. 41). Die slotwoorde van 'Malgas praat die see aan', naamlik 'weet/wat ek na lewe geslaan het/is 'n bres' (bl. 35), resoneer met, onder meer, 'Woordmens' uit die 2008-bundel Van roes en amarant waarin 
gesê word: 'Dié pennelekkerbekker/hy't probeer op sy manier/om na die lewe toe te leef' (Bekker 2008:98). Die neerdrukkende werklikhede van ' $n$ bestaan in ' $n$ woning voorsien van omvattende sekuriteitsmaatreëls word in 'Die patetiek van 'n blokhuis' opgevoer, maar sluit met die beeld van die geelvink wat met 'n grasspriet opdaag en 'nog 'n dag/met 'n kluitjie in die riet' (bl. 45) stuur. Die beskrywing van die 'wewer' se nes in hierdie gedig is treffend: " $n$ toeknypnier wat hang/aan die laagste tak oor die rivier'. Die driedelige 'Behouering' bestaan uit gevatte kwatryne, iets waarvoor Bekker bekend is. Die eerste hiervan, die amper aforistiese 'Selfie', lui soos volg:

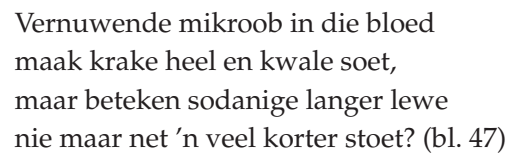

Afdeling vier, Ewe-eens, handel onder meer oor 'inlywing' by die dood en die kanon van (dooie) outeurs - oor die taksering van die self en wat dié gemaak en vermag het, veral wat betref die poësie. Daar is egter ook distansiëring hierby ingebou, waarskynlik ingegee deur die regsbetekenis van 'ingelyf' ('incorporated'), naamlik dat 'n korporasie 'n ander regsentiteit is as die stigter(s) daarvan, waardeur persoonlike aanspreeklikheid verminder. 'n Sleutelgedig in hierdie afdeling en die bundel is 'Bekker, ingelyf'. Die literêre selfontmoeting is 'soos - en daar lê die knoop -/om jou aan jou veters op te pluk:/Jy eindig met agter jou kop 'n voet/op 'n hoop' (bl. 50) - die graf word hierdeur opgeroep, soos dan ook in die verdere gedigverloop bevestig word. 'Teësinnig', wat direk daarop volg, is nóg so 'n sleutelgedig en een van die sterkstes in die bundel. Hierin bind die digter-spreker vir oulaas sy 'polkakoldas' (bl. 52) om die nek, om soos 'n wafferse dandy met bypassende Dalmatiese hond die 'woordstrate af' (bl. 52) te loop. Teleurstelling oor die resepsie van sy werk word in strofe twee uitgespreek:

\footnotetext{
Ek het my energie verspil,

my versies het gehang

soos ongerymde wasgoeddrade.

Ek het supers opgesit

waar die heuninguithalers

nooit gekom het nie.

My kersies in die pampoenspoke

het uitgebrand en al wat oorbly

is doodshoofmotte.
}

In die derde strofe word gesê dat die 'ruite van my strate/... lankal uitgeval [het]' (bl. 52), en met implisiete oproep van die inderdaad gekanoniseerde vroeë gedig 'Peins oor 'n plakkaat' (Bekker 1965:31) uit die debuutbundel Die klip sing, word gestel: "n Vroeë plakkaat hang skeef,/is nie 'n gedagte werd nie' (bl. 52). Die slot is treffend: baas en hond wou uiteindelik liewer omdraai, en '[b]oonop het hulle agtergekom/daar is reën/in die ou wind se waai.//En die laaste wasgoed moet af' (bl. 53). Met die tegnies trefsekere sonnet 'Wie is Bart Nel?' word die selftaksering met verwysing na die vroeë titel van Van Melle se roman, En ek is nog hy, op die spits gedryf. In afdeling vyf, Agterweë, word verder ingegaan op die persoonlike verlede, die digkuns inbegrepe. Die kern van hierdie afdeling is waarskynlik, naas die reeds genoemde 'Boedel' (bl. 61), die gedig 'Diachronie van 'n rymelaar'. Die misnoeë of vertwyfeling wat die resepsie van sy werk by die spreker wek, word met laasgenoemde twee gedigte verder geboekstaaf. Wat egter in 'Diachronie van 'n rymelaar' gebeur, is dat die fokus nou wegskuif van die onaandagtige en aanmatigende lesers/ kritici na 'n verwoording van wantroue in woorde en betekenis as sodanig:
sinnigheid vir woorde
sterf in hul diaspora
met betekenisse smokkel
swerf hul na oorde
waar net die eggo's koggel
wyd en wyer lê die spore
tot ook dié in kieselbrak verbrokkel (bl. 63)

Die digter het nie beheer oor wat van sy woorde word nie. Waarvan die digter wel seker bly, is die liefde wat met die lewensmaat gedeel word, soos gedemonstreer in afdeling ses, Kersgevoelig in die liefde. Veral die saam oud word staan hier in die kollig, en nogeens word die digterskap hierby betrek, onder meer in die sonnetvorm: 'By herinnering aan 'n doodgaan' (bl. 71) en 'Aanspraak ('n Sonnet vir A. op 78)' (bl. 75). Die harde werk en kundigheid wat hierdie oú ambagtelike vorm vereis, is 'n integrale deel van die 'geskenk' aan die beminde. In noue skakeling met 'Diachronie van 'n rymelaar', waarin (leë) betekenisgewing enigsins ontluister word, word die (konkrete) daad in "n Don herwin veld', met klaarblyklike heenwysing na Jan F.E. Celliers (s.a.) se 'Waghondjies', dan ook positief gemarkeer. Hierdie gedig sluit soos volg:

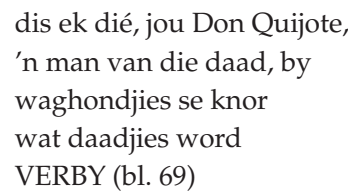

'n Mens sou amper kon sê dat die woord in hierdie afdeling (en bundel), al is dit dan ook soms op voortvarende wyse, by die daad gevoeg word, en nie andersom, soos die uitdrukking konvensioneel lui nie. Die slot van 'Teen die weerloosheid' voltrek die daad (van omsluiting en vasknoop) deur hegte woordsluiting, onder meer danksy die eindrym, naamlik 'gekoop' wat uiteindelik in die slotreël verbind met 'knoop':

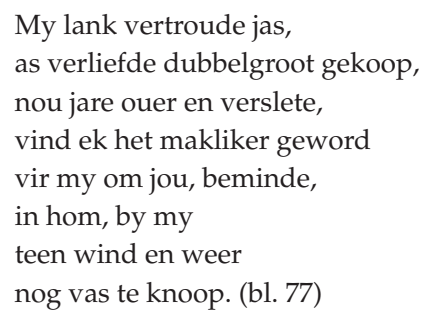

In die daaropvolgende afdeling, Mens ontpop, word onder meer eensaamheid, relasionaliteit, medemens(likheid) en dialoog getematiseer. Een van die hoogtepunte in hierdie afdeling is nóg 'n kenmerkend satiriese Bekker-kwatryn, 'Ou aktrise verjong': 
Vir haar herbelyning kry sy paradyslike begrip, selfs beentjies word verwyder in die nip and tuck en as bonus hoop sy die volmaakte maat

kom na vore uit haar weggesnyde rib. (bl. 87)

Die slotafdeling heet Frontaal. Hierin word ingeteleskopeer op die verlede, op die verhaaleinde en weggaan, maar steeds kordaat toegekeer na die lewe - frontaal naak, soos die titel van hierdie afdeling dan ook suggereer. In aansluiting by die deurlopende spelelement in Bekker se werk en die vooropstelling van die kind en jeugdigheid - oftewel die kind ín die volwassene en oumens - word in 'Lyf op die spel' aangedui dat hy wat 'geskryf het oor veldtogte, in ouer oë banaal,/springhase voor opgeskote seuns se koplampe' (bl. 100) en boonop 'seunsagtig onbehoed wou leef' (bl. 101), eintlik sou moes 'uitsien na hierdie [laaste] avontuur' (bl. 101), naamlik om 'hierdie aarde [te] moet verlaat' (bl. 100). Die versugting word uitgespreek dat, as daar nou 'wankel in my wik [is], mag dit/kortstondig wees teen 'n ewige paradys' (bl. 101). 'n Hoogtepunt van die afdeling en van die bundel is die bykans volledig Shakespeariaanse sonnet 'Laat renaissance' waarin heelwat van die bundel en Bekker se poëtika byeenkom. Die titel slaan nie net op die kultuurgeskiedkundige gegewe waarvan die sonnetvorm deel is nie, maar waarskynlik ook op die late bloei wat moontlik is in die bejaarde se lewe, asook in dié van die digter van gevorderde leeftyd. Die frontale naaktheid van Michelangelo se Dawidbeeld wat 'middelburgers [laat] omdraai in hul graf' en die lewendes 'uitdruklik hoog beswaard' (bl. 107) maak, skakel met Bekker se bevestigende lewensingesteldheid, waarby ook dikwels die satiriese voorstelling van sake en die uitdaging van gevestigde opvattings en sensibiliteite hoort. Die tweede strofe lui:

Vingerwysing na dáár onder het egter ook verset ontketen: Die kunswerk wys immers 'n lyf wat opgaan in sy wapen die slingervel, die natgelekte klip. Dit is tog nie obseen, dié swaai wat ' $n$ beer sy stormloop kan laat verander. (bl. 107)

Hiermee is '[d]ie teerling gewerp' vir allerlei soorte simboliese 'verlengstukke van persone' (bl. 107), vanaf 'gholfstokke' tot 'saksofone' (bl. 107), word aan die begin van die sestet verklaar. Trouens, en dit word nie in die gedig gesê nie, maar moontlik geïmpliseer, het die sonnet teen die laat Renaissance 'n evolusie ondergaan wat dit omskep het in 'n instrument waarmee 'n verskeidenheid temas, en nie net die liefde nie, verken kon word, soos dan ook in hierdie sonnet van Bekker die geval is. Die rymende slotkoeplet - 'almal kennelik koel en afsydig, gereed vir die invloed/en die stuwende definiëring van die polsende bloed' (bl. 107) aktiveer 'n bekende Bekker-tema, te wete 'invloed', soos gekonsolideer in sy kortverhaal 'Die invloed' (Bekker 1992:129-133), waarin dit verhaalspesifiek gaan oor die invloed as riviermonding, maar ook die uitwerking wat mense (intellektueel, geestelik, liggaamlik) op mekaar het en die wisselwerking van (inter)tekste. Die Dawidbeeld (waarna in 'Laat renaissance' verwys word) is nie net ' $n$ belangrike artistieke verwysingspunt in die Westerse kultuurgeskiedenis nie, maar 'beliggaam' ook 'n lewenshouding wat sentreer in (oorgehaal wees tot) die daad en agentskap. Daardeur staan hierdie standbeeld in meer as een opsig vir die digter model.

In die slotgedig, 'Toe ek my kom kry', word die persoonlike en digterlike einde vanuit 'n agternaperspektief voorgestel as soek/weg wees, met die ontluisterende besef dat 'geen saamtrekke gereël [is] nie,/geen soekgeselskappe georganiseer nie' (bl. 110). Dan volg egter weer iets van die tipiese Bekker-opstelling teenoor die lewe, wat verwoord word met implisiete toespeling op Van Wyk Louw se gedig 'Klein variasie op die woord "gaan"' in die bundel Tristia (1987 [1962]):

Ons was so aan die gaan gewend

dat ons gemeen het: gáán is goed.

Maar elke gáng word: self-orent.

Die end is bitter. En dis end. (Van Wyk Louw 1987 [1962]:24)

Op Van Wyk Louw se vers oor die einde van gaan, bou Bekker aweregs voort:

Dit alles na die maan geblaas

toe ek van 'gaan' 'kom' probeer maak het,

van 'verloor' sonder omhaal ' $k r y$ '

om so 'n ewige vermissing te vermy. (bl. 110)

Wat ek in hierdie resensie na vore gehaal het, is die sterk momente in Voor ek my kom kry, die betreklik helder retoriese lyn wat wel daarin gevolg kan word. Daar is heelwat gedigte wat minder noemenswaardig is, of (nog) nie vir my uit die nou reeds bekende Bekker-duisterheid getree het nie. Deur volhardende lees kan moontlik uiteindelik ook van daardie gedigte nader ontsluit word. Wat egter veral in hierdie bundel van Bekker na vore kom, is die uithef van 'doen' bo 'beteken', en myns insiens skuil hierin 'n belangrike sleutel. Die naspeur van wat Bekker se werk tog alles sou beteken, is ' $n$ gevestigde onderneming van die Bekker-kritiek wat graag stilstaan by die raaiselagtighede. Dis dalk meer bevorderlik om hierdie bundel, en Bekker se werk in die algemeen, óók te lees in terme van wat dit (wil) doen, soos ek in my lesing begin aantoon het. Die duisterheid en ontwykendheid van Bekker se poësie vorm moontlik deelvan die spel met die leser (oftewel die 'heuninguithalers', bl. 52) én van die doelbewus opgestelde individualiteit en weerbaarheid.

Nietemin is daar heelwat te oes vir meelewende lesers, en ook heelwat te wen deur die Bekker-lewenshouding in digterlike formaat te beleef: die rats retoriese gang en speelse taal- en versaanwending besit én demonstreer iets seëvierends, wat 'n opbeurende leeservaring in die hand werk. Bekker se digkuns kan as vernufpoësie beskryf word, maar dan met bepaalde voorbehoude, en hier vind ek aansluiting by Daniel Hugo (1988) se proefskrif oor die Afrikaanse vernufpoësie. Hy stel 'n inklusiewe beskouing van die vernufpoësie voor: dit gaan in hierdie soort gedig oor 'n intellektuele spel met die taal en die versvorm, en nie om spel bloot ter wille van spel nie. Hy haal J.C. Steyn aan wat dit in hierdie verband het oor 'n 'fenomenologiese spel met taal' (Hugo 1988:1). Hugo (1988) onderskei tussen 
vernufpoësie en geestige poësie, maar dui aan dat daar eerder 'n graadverskil tussen dié twee is: waar die klem by eersgenoemde op bv. woord- en verstegniese spel val, is geestige poësie in die eerste instansie ingestel op die denkinhoud en die retoriese voorstelling daarvan. Geestige poësie is dan ook heel dikwels ernstig, en nie noodwendig 'lig' nie. Myns insiens is Bekker se werk veral geestig ('witty'), en die vernuftige taal- en vormelemente staan in diens dáárvan. Meestal skryf Bekker, ook weer in Voor ek my kom kry, meer uitgesponne gedigte wat 'n voortstuwende argumentasielyn bevat, en die leser moet byhou. Ook die korter gedigte, bv. die kwatryne, getuig van geestigheid én vernuf.

\section{Literatuurverwysings}

Bekker, P., 1965, Die klip sing, Nasionale Boekhandel, Kaapstad.

Bekker, P., 1992, Lag byvoorbeeld, Tafelberg, Kaapstad.

Bekker, P., 1993, Rasuur, Tafelberg, Kaapstad.

Bekker, P., 2008, Van roes en amarant, Protea Boekhuis, Pretoria.

Bekker, P., 2013, Atlas teen die vergeetrivier, Protea Boekhuis, Pretoria.

Celliers, J.F.E., s.a., Bloemlesing uit die gedigte van Jan F.E. Cellliers, Afrikaanse PersBoekhandel, Johannesburg.

Hugo, D.J., 1988, Die digter en sy middele: 'n Ondersoek na die vernufpoësie in Afrikaans, Universiteit van die Oranje Vrystaat, Bloemfontein (ongepubliseerde doktorale proefskrif).

Odendal, F.F. \& Gouws, R.H., 2005, HAT: Verklarende handwoordeboek van die Afrikaanse taal, Pearson, Kaapstad.

Van Wyk Louw, N.P., 1987 [1962], Tristia en ander verse, voorspele en vlugte 1950-1957, Human \& Rousseau, Kaapstad. 